\title{
COVID-19 from a Perspective of Neuromuscular Diseases: Meeting the Challenges
}

Dear editor,

The new severe acute respiratory syndrome coronavirus 2 epidemic is imposing immense strain on the health systems in several countries. The growth of the epidemic has led the WHO to declare the 2019$\mathrm{nCoV}$ disease as a global pandemic [1]. Coronavirus disease 2019 (COVID-19) pandemic has the potential to affect patients with neuromuscular diseases. The evaluation of the overall risk of COVID-19 in patients with neuromuscular diseases depends on several factors: The specificity of the neuromuscular disease, the general condition, the presence of other comorbidities, age, and the type of immunosuppressive treatment they receive. It is important to emphasize the fact that most patients with neuromuscular disease are not expected to suffer from severe complications due to coronavirus infection. Corona infections can affect certain myopathies. In a recent study published in China, related to COVID-19 is shown that hospitalized patients experienced fatigue and myalgia (44-70\%) and increased creatine kinase $(33 \%)$ in the serum [2]. Apart from this, a third of hospitalized patients infected with the coronavirus had rhabdomyolysis [3]. All of this point to the fact that coronavirus infection may be responsible for viral myositis. In addition, is the finding that some of the critical cases have developed polyneuropathy or myopathy [4]. On the other hand, it is well known that infection is a trigger for exacerbation of certain neuromuscular diseases. There are no data that measured the risk of exacerbation as a result of coronaviruses infection for neuromuscular disorders. However, in one retrospective study, COVID-19 infection was a leading reason for the exacerbation of myasthenia gravis [5]. As a result of this, an increased incidence of exacerbations of certain neuromuscular diseases should be expected, as well as the appearance of new clinical presentations during this pandemic. It is important to note that there are still no neuromuscular disease-specific recommendations for patients who are infected with the coronavirus. Observation is recommended in patients at high and medium risk, especially in those patients where there is a possibility of a decrease in respiratory function. Last but not least, we would like to emphasize the need for reorganization of clinical care for these patients [6]. The goal is to reduce exposure of patients to areas where the coronavirus could be found. Moreover, non-urgent or outpatient care is remarkably reduced. In conclusion, we must learn to apply our clinical practices to reduce the complications that may occur in patients with neuromuscular disease due to COVID-19. The primary goal is to develop evidence-based medical practices to reduce morbidity and mortality. Collaboration among institutions worldwide will be able to give us the data needed for planning management for neuromuscular disorders with COVID-19 and maintain clinical research against strong challenges.

\section{References}

1. Contreras GW. Getting ready for the next pandemic COVID-19: Why we need to be more prepared and less scared. J Emerg Manag. 2020;18(2):87-9. https://doi.org/10.5055/jem.2020.0461 PMid:32181864

2. Wang D, Hu B, Hu C, Zhu F, Liu X, Zhang J, et al. Clinical characteristics of 138 hospitalized patients with 2019 novel coronavirus infected pneumonia in Wuhan, China. JAMA. 2020;323(11):1061-9. https://doi.org/10.1001/jama.2020.1585 PMid: 32031570

3. Chen LL, Hsu CW, Tian YC, Fang JT. Rhabdomyolysis associated with acuterenalfailureinpatientswithsevereacuterespiratorysyndrome.Int $J$ Clin Pract. 2005;59(10):1162-6. https://doi.org/10.1111/j.1368-5031.2 005.00540.x

PMid:16178983

4. Tsai LK, Hsieh ST, Chao CC, Chen YC, Lin YH, Chang SC, et al Neuromuscular disorders in severe acute respiratory syndrome. Arch Neurol. 2004;61(11):1669-73. https://doi.org/10.1001/ archneur.61.11.1669

PMid:15534177

5. Gummi RR, Kukulka NA, Deroche CB, Govindarajan R. Factors associated with acute exacerbations of myastheniagravis. Muscle Nerve. 2019;60(6):693-9. https://doi.org/10.1002/mus.26689 PMid:31469909

6. ANEM COVID. Available from: https://www.aanem.org/Practice/ COVID-19-Guidance. [Last accessed on 2020 Apr 03]. Ivan Barbov ${ }^{1}$, Goce Kalcev ${ }^{2}$

${ }^{1}$ Department of Neuromuscular Disorders, University Clinic for Neurology, Skopje, Republic of Macedonia; ${ }^{2}$ International $P h D$ in Innovation Sciences and Technologies, University of Cagliari, Italy 